\title{
ATIVIDADE EXPERIMENTAL DE BAIXO CUSTO: O CONTRIBUTO DO LUDIÃO E SUAS IMPLICAÇÕES PARA O ENSINO DE FÍSICA
}

\author{
JOÃO BATISTA DA SILVA, GILVANDENYS LEITE SALES ${ }^{\dagger}$ \\ Programa de Pós-Graduação em Ensino de Ciências e Matemática (PGECM) \\ do Instituto Federal de Educação, Ciência e Tecnologia do Ceará (IFCE)
}

\begin{abstract}
Resumo
Este artigo consubstancia uma pesquisa bibliográfica centrada num interesse de apresentar as principais contribuições do ludião para o ensino de Física. Inicialmente foi realizado um levantamento da produção científica nacional sobre a utilização desse experimento de baixo custo em quatro bases de dados: o Google Acadêmico, Directory of Open Access Journals (DOAJ), Bielefield Academic Search Engine (BASE) e o portal de periódicos da CAPES. A pesquisa revelou que, apesar do Ludião ser bastante utilizado em eventos como feira de ciências, há uma carência de artigos publicados em periódicos. Apesar da carência, foi identificado que esse experimento é potencialmente viável para contribuir com o ensino de Física, principalmente por ser lúdico, envolvente, de baixo custo e acessível, podendo ser construído pelo próprio aluno com materiais encontrados em seu cotidiano.
\end{abstract}

Palavras-chave: Ludião, Ensino de Física, Hidrostática.

\footnotetext{
*E-mail: joaobathista82@ hotmail.com

†E-mail: denyssales@gmail.com
} 


\begin{abstract}
This article presents a bibliographical research centered on an interest in presenting the main contributions of the Cartesian diver to Physics education. Initially a survey of the national scientific production on the use of this low-cost experiment was carried out in four databases: Google Academic, Directory of Open Access Journals (DOAJ), Bielefield Academic Search Engine (BASE) and the CAPES journal portal. The research revealed that although Cartesian diver is widely used in events such as science fair, there is a shortage of articles published in journals. In spite of the lack, it was identified that this experiment is potentially feasible to contribute to Physics education, mainly because it is playful, engaging, Low-Cost, and accessible, and can be constructed by the student himself with materials found in his daily life.
\end{abstract}

Keywords: Diver, Physics education, Hydrostatics.

\title{
1 INTRODUÇÃO
}

A grande maioria das escolas brasileiras não tem estrutura adequada e nem equipamentos básicos para aulas experimentais de Física. O mais agravante é que as poucas que tem, muitas vezes nem usam. Além disso, as más condições de trabalho é um fator, dentre os vários, que contribui para a crise do ensino de Física na Educação Básica (MOREIRA, 2017). Além disso, a falta de atividades experimentais em laboratórios didáticos contribui para que esses alunos, principalmente aqueles oriundos de classes sociais economicamente menos favorecidas, tenha uma formação científica e tecnológica bastante deficiente (SILVA; LEAL, 2017).

Nesse sentido, Prado e Ferracioli (2017) destacam:

A maior parte das escolas públicas do Brasil, não possuem laboratórios de Ciências, sendo este um entrave para as aulas experimentais nas escolas. Assim, materiais para a atividade experimental tornam-se mais difíceis ainda. Desta forma, buscamse alternativas para a realização de atividades experimentais com os estudantes de ensino médio na disciplina de Física. Muitas atividades experimentais são realizadas em sala de aula e/ou em espaços alternativos das escolas como o pátio e a quadra de esportes. Os materiais para a realização da atividade experimental são providenciados pelos próprios estudantes, visto que as escolas também não possuem recursos para aquisição dos mesmos.

As dificuldades que afetam o ensino de Física não são recentes e já foram diagnosticados há muitos anos. As propostas apresentadas apontam para possíveis soluções, como o ensino voltado para a participação plena dos alunos (ARAÚJO; ABIB; 2003). 
De modo convergente a esse âmbito de preocupações, o uso de atividades experimentais como estratégia de ensino de Física tem sido apontado por professores e alunos como uma das maneiras mais frutíferas de se minimizar as dificuldades de se aprender e de se ensinar Física de modo significativo e consistente (ARAÚJO; ABIB; 2003, p.176).

Todavia, as atividades experimentais, que deveriam também ser desenvolvidas em laboratórios, acabam sendo substituídas por mais aulas teóricas com excessivo formalismo matemático, afastando-se, cada vez mais, dos aspectos fenomenológicos e de práticas pedagógicas que utilizem ferramentas didáticas para facilitar a aprendizagem dos alunos (CUNHA, 2008; SILVA et al. 2017).

Vale destacar que, ambas, sem dúvida, são importantes no processo de ensino, todavia, as aulas de Física sem práticas experimentais acabam se tornando enfadonhas e sem motivação. Sendo assim, o ato de ensinar não pode ser mais entendido como uma mera transmissão do conhecimento científico (ARNONI; KOIKE; BORGES, 2004).

É importante destacar, que apenas as aulas teóricas, por si só, não são mais capazes de despertar o interesse dos alunos. Um dos motivos da desmotivação é a concepção, por parte dos alunos, de que as aulas de física são apenas teóricas, sem qualquer vinculação com a realidade. Ademais, o aluno desmotivado tende a se afastar do conhecimento científico.

Esse fato dificulta ainda mais o trabalho do professor, que além de não poder contar com uma estrutura adequada para atividades experimentais na escola, ainda tem que desenvolver estratégias para motivar o interesse do aluno pela disciplina.

O interesse e a curiosidade dos alunos são variáveis que devem ser consideradas no processo de ensino da disciplina. Nesse sentido, surgem os experimentos de baixo custo, cujos objetivos são tentar motivar o aluno em atividades experimentais, aproxima-lo da ciência, e contornar a falta de laboratórios equipados nas escolas, ou pelo menos tentar amenizar a situação (DUARTE, 2012).

Esses experimentos aos poucos se tornaram uma alternativa potencial para o ensino de Física, não para substituir o laboratório, mas para contornar a situação causada pela sua falta, proporcionando aos alunos experiências nas quais eles possam desenvolver habilidades como: observar o fenômeno, estabelecer hipóteses, manipular materiais e outras coisas. Além disso, os experimentos de baixo custo possibilitam que o aluno construa seu próprio aparato experimental com materiais de fácil obtenção, disponíveis e acessíveis, encontrados no seu cotidiano (DUARTE, 2012).

Isto posto, com amparo numa pesquisa bibliográfica, este artigo tem como objetivo apresentar os principais contributos do ludião para o ensino de Física. Nesse sentido, na próxima seção deste trabalho é realizada a apresentação do experimento e de alguns princípios envolvidos em seu funcionamento. Em seguida, na seção 3 são descritos os caminhos metodológicos percorridos nesta investigação. Por conseguinte, na seção 4, são relatadas as contribuições do ludião para o ensino de Física. Por fim, na última seção são apresentadas as considerações finais. 


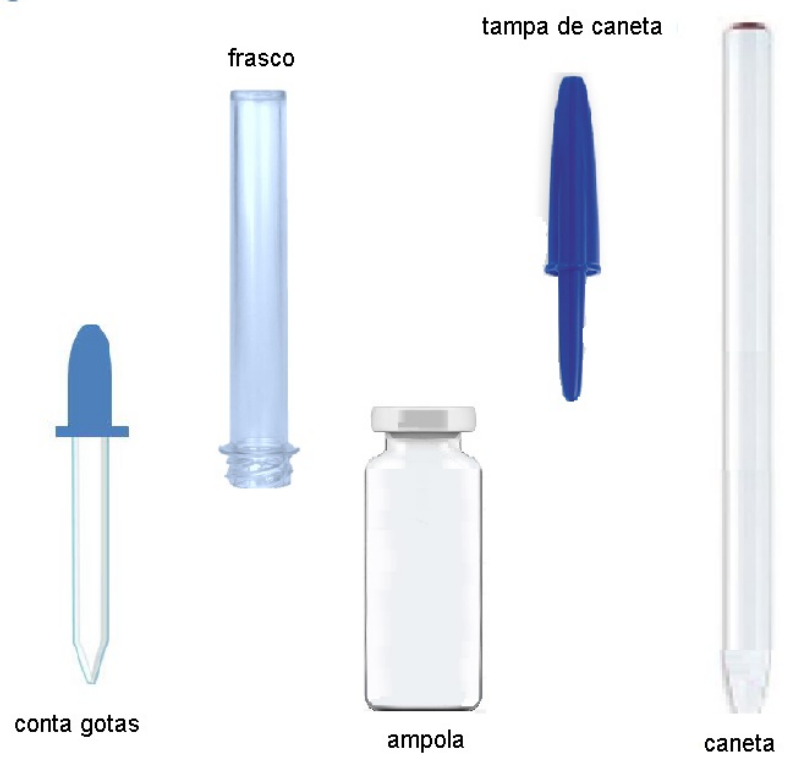

Figura 1: Alguns objetos que podem ser utilizados para construir o ludião.

\section{O LUDIÃO}

O Ludião, também conhecido como mergulhador cartesiano, é um experimento de baixo custo, muito utilizado em eventos, como feira de ciências, devido sua capacidade de atrair a atenção das pessoas por ser simples, interativo, e dinâmico.

O experimento é constituído de três componentes básicos: água limpa, uma garrafa PET transparente, e um frasco pequeno. Para proporcionar uma melhor visualização dos fenômenos que ocorrem no interior do ludião, propõe-se que seja utilizado um frasco com maior transparência, como um desses que, normalmente, são utilizados em amostras grátis de perfumes. Caso não seja possível encontrá-lo facilmente, ele poderá ser substituído por outro objeto com características semelhantes como um conta gotas, uma tampa de caneta, uma ampola de vidro, um corpo de caneta sem o tubo e sem ponta entre outras coisas (Figura 1).

Para montar o experimento a garrafa deve ser completamente preenchida com água. Em seguida o frasco também deve ser preenchido com água, só que aproximadamente até 3/5 de sua capacidade máxima, de maneira que a densidade do conjunto (frasco + ar + água interna do frasco) seja um pouco menor do que a densidade do fluido em que deverá ficar imerso (a água da garrafa PET).

O frasco com água deve ser invertido e colocado dentro da garrafa cheia. Logo após, a garrafa deverá ser totalmente fechada, para possibilitar o estudo de alguns fenômenos envolvidos no sistema, entre eles, a subida e descida do ludião causados pelas influências do meio externo (ARNONI; KOIKE; BORGES, 2004).

Uma das dificuldades encontradas na construção desse experimento é encontrar o equilíbrio, a flutuabilidade e a verticalidade do ludião. Por isso, a maioria dos experimentos utiliza um material extra para contrapeso (massa de modelar, clipes, arruela de metal, etc.) para assumir a função do lastro. Essa é a 


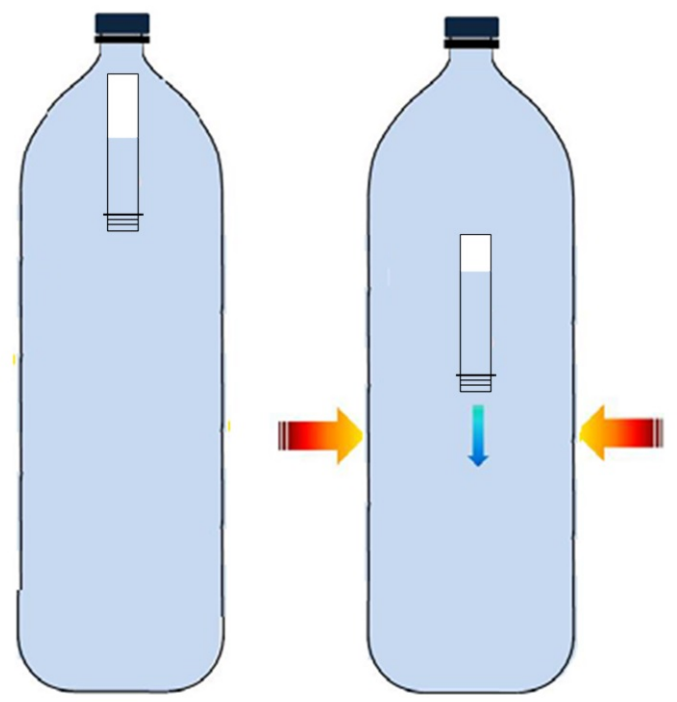

Figura 2: Funcionamento do sistema do ludião.

mesma função que existe nas embarcações, ou nos submarinos, para garantir que o centro de gravidade (CG) do corpo fique abaixo do centro de pressão (CP), caso contrário, a embarcação adernaria (JESUS; MARLASCA; TENORIO, 2007). Em síntese, se o lastro colocado for demasiadamente pesado faz com que o ludião afunde imediatamente.

Considerando essa dificuldade que normalmente é encontrada na montagem desse experimento, neste trabalho foi utilizado um frasco transparente, desses que normalmente vem em amostra grátis de perfumes, pois, apesar da transparência, ele já tem uma espécie de "lastro embutido" (Figura 3b).

Para o funcionamento do experimento, o ludião deve estar na parte superior da garrafa. Então, ao apertar a garrafa o ludião afunda, e ao aliviar a pressão ele volta a subir (Figura 2).

Isso acontece devido a sua sensibilidade à variação de pressão externa exercida sobre a garrafa, fazendo com que cada vez que for exercido um acréscimo de pressão ele desça, e ao retornar as condições iniciais de pressão ele suba.

Na tentativa de explicar as variáveis envolvidas nesse fenômeno, na maioria das vezes, o ludião é utilizado com o objetivo de demonstrar, principalmente, os princípios hidrostáticos de Pascal e de Arquimedes (JESUS; MARLASCA; TENORIO, 2007).

\subsection{O princípio de Pascal}

De acordo com o princípio de Pascal, qualquer acréscimo de pressão exercido em um ponto de um líquido incompressível em equilíbrio é transmitido integralmente a todos os pontos desse líquido. Ou seja, sempre que for exercida uma força externa as paredes da garrafa, está produzirá um incremento de pressão na água, e consequentemente, esse incremento será transmitido a todos os pontos do fluido, inclusive nas paredes internas da garrafa e do frasco (Figura 3a).

Pressupondo que a garrafa esteja totalmente cheia e fechada, é possível visualizar as consequências da 


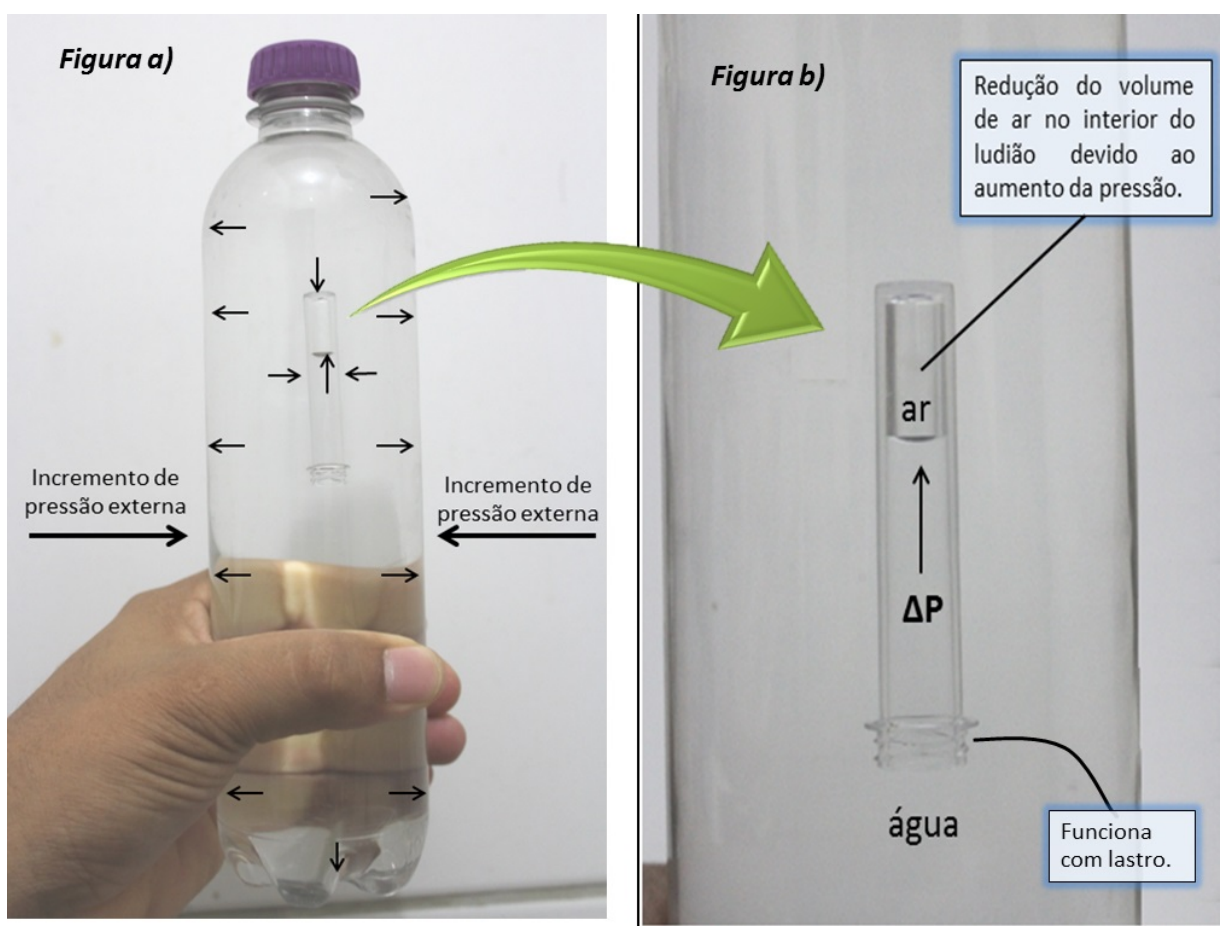

Figura 3: Diagrama ilustrativo da variação de pressão aplicada na garrafa e suas implicações na variação do volume interno do ar confinado no interior do ludião.

variação da pressão da água pela variação do volume de ar dentro do ludião (Figura 3b).

Essa variação do volume acontece porque o frasco é aberto na parte inferior. Nesse caso, sempre que houver um incremento de pressão no fluido incompressível (a água), esse incremento comprimirá o ar (fluido compressível) no interior do ludião, e consequentemente, o volume de ar em seu interior diminuirá de acordo com a pressão exercida no fluido.

Quanto mais se aumenta a compressão do ar no interior do frasco, maior será o aumento da densidade do ludião em relação ao fluido, fazendo que que ele afunde. Ao diminuir a pressão exercida na garrafa PET, o ar comprimido volta às condições iniciais, e o ludião tornará a subir. O movimento de sobe e desce torna o experimento atrativo, interativo, divertido e dinâmico.

Além do princípio de Pascal, existe outro que também pode auxiliar na compreensão do fenômeno relacionado com a subida e descida do ludião, este é o princípio de Arquimedes.

\subsection{O princípio de Arquimedes}

De acordo com o princípio de Arquimedes, quando um corpo é imerso em um fluido em equilíbrio, sob a ação da gravidade, ele recebe do fluido uma resultante de forças que tem direção vertical, direcionada para cima e com intensidade igual ao peso do fluido deslocado. Essa força que o fluido exerce sobre o corpo foi denominada empuxo. Este príncipio também se aplica ao funcionamento do ludião.

O módudo do empuxo total (Etotal) exercido pelo fluido no ludião (frasco + ar) é igual ao valor do peso do líquido deslocado. Ou seja, o valor do empuxo total é variável, dependendo diretamente do volume de 


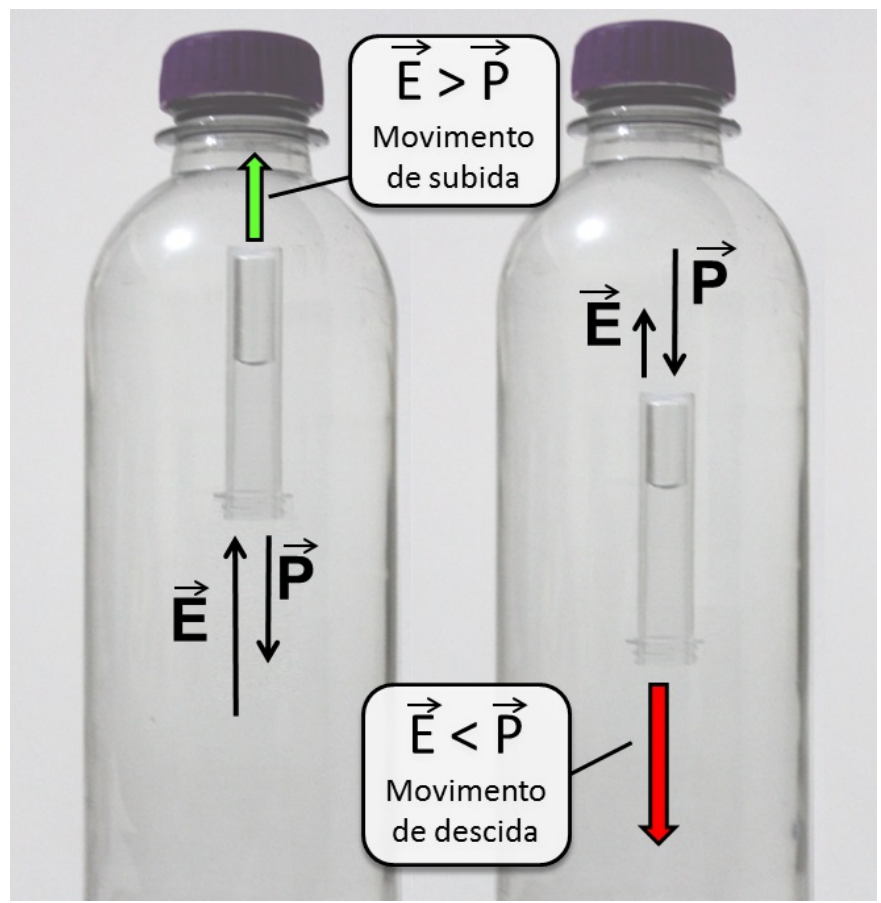

Figura 4: Diagrama ilustrativo da variação do empuxo em dois momentos e suas implicações para o movimento de descida e subida do ludião.

ar em seu interior e de sua parcela de imersão no fluido

$$
E_{\text {total }}=E_{1}+E_{a r}
$$

onde $E_{1}=\rho g V_{1}, E_{a r}=\rho g V_{a r}, V_{1}$ e $V_{a r}$ são os respectivos empuxos e volumes do ludião e do ar em seu interior, quando o ludião está totalmente imerso e $\rho$ é a densidade do líquido.

Já o módulo do peso $(\mathrm{P})$ do ludião é constante, pois depende apenas da massa do frasco e da massa do ar e é dado por

$$
P_{\text {total }}=P_{1}+P_{a r}
$$

sendo $P 1=m_{1} g$ e $P_{a r}=m_{a r} g$ os respectivos pesos do recipiente de plástico ou ludião e da massa de ar em seu interior.

Nesse sentido, quando o ludião está em repouso ou equilíbrio estável próximo à superfície do líquido na garrafa, ele não afunda porque a sua densidade é menor que a densidade do fluido no qual está imerso, sendo que o empuxo será maior do que o peso. Contudo, quando o ar dentro do ludião se comprimir em virtude de uma compressão externa que causa aumento de pressão no sistema, de maneira que ludião se torne mais denso que a água, ele consequentemente, passará a submergir (Figura 4).

A pressão do ar (par) no interior do ludião a uma profundidade h, medida entre a superfície do líquido na garrafa e a interface de separação entre o ar com o líquido no interior do ludião, é dado por

$$
\text { par }=p_{\text {sup }}+\rho g h,
$$


onde psup é a pressão do ar na superfície do líquido dentro do ludião. O valor de psup pode ser modificado por uma variação na pressão, compressão ou descompressão externa na garrafa.

Suponha um aumento de pressão do ar no interior do ludião, o que reduz seu volume, segundo a equação de Clapeyron de estado dos gases perfeitos, temos

$$
p_{a r} \cdot V_{a r}=n R T,
$$

isolando $V_{a r}$, tem-se

$$
V_{a r}=n R T / p_{a r},
$$

sendo $\mathrm{n}$ o número de moles do gás, $\mathrm{R}$ a constante universal dos gases e $\mathrm{T}$ a temperatura absoluta do gás, considerada constante e igual à temperatura ambiente. A redução do volume de ar no interir do ludião implica numa diminuição de seu empuxo (Ear). Com o início da submersão tem-se um aumento da profundidade (h) da massa de ar contida no ludião, o que faz aumentar ainda mais sua pressão, acarretando a redução em seu empuxo (Ear), dada pela equação

$$
E_{a r}=\rho g V_{a r}=\rho g n R T / p_{a r}=\rho g n R T /\left(p_{\text {sup }}+\rho g h\right)
$$

Conforme Equação 6 a relação peso/empuxo é essencial para determinar o movimento de subida e descida, sendo o empuxo sobre o ar contido no ludião a variável de controle. Todavia, é importante destacar que durante o movimento, enquanto o peso do ludião permanece constante, o empuxo fica variando.

Considerando as implicações do princípio de Arquimedes no funcionamento do ludião, o responsável pelo seu mergulho/imersão é a variação do empuxo, ao invés da variação de seu peso (JESUS; MARLASCA; TENORIO, 2007).

\section{PROCEDIMENTOS METODOLÓGICOS}

Esta seção do presente artigo apresenta uma síntese dos procedimentos, não aleatórios, e dos caminhos percorridos para o levantamento realizado da produção científica sobre a utilização do experimento de baixo custo, denominado de "ludião", no ensino de Física. Para realização da pesquisa foram utilizadas quatro bases de dados: o Google Acadêmico, Directory of Open Access Journals (DOAJ), Bielefield Academic Search Engine (BASE) e o portal de periódicos da CAPES. Estas bases foram escolhidas e utilizadas por serem de circulação disponível gratuitamente na internet.

A pesquisa foi realizada entre os meses de julho e agosto de 2017. Durante esse período, foi analisada a produção científica publicada nos últimos 15 anos, especificamente entre os anos de 2002 até 2017.

Das quatro bases de dados, a busca no Google Acadêmico foi a única que apresentou resultados. As demais bases de dados, BASE, DOAJ e o portal de periódicos da CAPES, não registraram nenhum resultado para a busca. Na Tabela 1 é apresentado uma síntese dos resultados quantitativos da busca.

Para realização da pesquisa no o Google Acadêmico, foi introduzido o descritor primário "ludião" sem restrição alguma, onde o descritor pudesse está em qualquer parte do texto, nesse caso foram apresentados 102 resultados. Essa estratégia foi escolhida por causa dos poucos trabalhos publicados sobre o tema.

Após a leitura dos resumos, foram excluídos 94 trabalhos por não serem pertinentes ao tema, ou por serem trabalhos repetidos. Restando assim, apenas 8 trabalhos que foram consideradas relevantes e que 
Revista do Professor de Física • Brasília, vol. 2, n. 2 • 2018

Tabela 1: Busca em base de dados do termo Ludião

\begin{tabular}{|c|c|c|}
\hline Base & Trabalhos Encontrados & Trabalhos Selecionados \\
\hline BASE & 0 & 0 \\
\hline DOAJ & 0 & 0 \\
\hline Google Acadêmico & 102 & 8 \\
\hline Periódicos CAPES & 0 & 0 \\
\hline Total & $\mathbf{1 0 2}$ & $\mathbf{8}$ \\
\hline
\end{tabular}

pudessem contribuir para a fundamentação teórica da presente pesquisa. Ademais, deste universo, apenas 2 trabalhos (PIMENTEL; YAMAMURA, 2006; JESUS; MARLASCA; TENORIO, 2007) trazem no título, de forma explicita, o termo "Ludião".

\section{CONTRIBUIÇÕES DO LUDIÃO PARA O ENSINO DE FÍSICA}

Com o objetivo de valorizar tanto o conhecimento cotidiano dos alunos e o conhecimento científico a ser ensinado, Arnoni, Koike e Borges (2004) utilizam o ludião para promover o ensino através da problematização, de maneira que os estudantes possam articular o saber cotidiano com o saber científico durante o processo de ensino e aprendizagem. Seguindo uma sequência previamente estabelecida e orientada pelo professor, a atividade experimental foi aplicada com a finalidade de garantir a aprendizagem associando experimentos práticos, baseados em conceitos científicos, aos conhecimentos prévios do aluno, oriundos do cotidiano.

Nesse sentido, Arnoni, Koike e Borges (2004 p.290) destacam:

Foi muito interessante a reação dos alunos; num primeiro momento, recorreram aos conceitos científicos decorados e, aos poucos, foram dando conta de que as definições não eram suficientes para explicar o movimento observado. Esse fato demonstra a ineficiência do ensino pela memorização, os alunos haviam decorado a definição e/ou a fórmula e não conseguiam usá-las para responderem questões de compreensão e, ainda, não analisavam as partes e nem relacionavam as partes com o todo.

De acordo com os autores supracitados, a tônica da discussão do experimento girou em torno da subida e descida do ludião. A presença desse fenômeno potencializou principalmente a discussão de conceitos como pressão, densidade, e a relação estabelecida entre eles na explicação do experimento.

Além de trabalhar esses conceitos, Sales e Vianna (2013) utilizam o ludião para promover uma atividade investigativa e trabalhar suas aplicações, cujo objetivo é proporcionar um aprendizado mais efetivo para o aluno.

Nessa perspectiva de aprofundar conceitos envolvidos no experimento, Jesus, Marlasca e Tenorio (2007) utilizam uma versão mais sofisticada do ludião, a qual é constituída por um tubo rígido de acrílico conectado por uma mangueira a um manômetro e a uma seringa. A função da seringa é controlar a pressão externa aplicada, sendo monitorada pelo manômetro. Para a construção do ludião foi utilizado um pequeno 


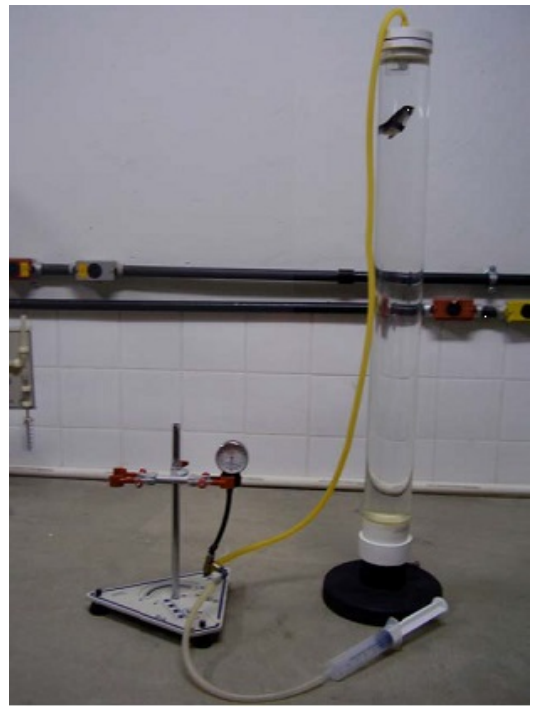

Figura 5: O ludião com mais componentes. Fonte: Jesus, Marlasca e Tenorio (2007)

recipiente cúbico de acrílico amarrado a um boneco em forma de peixe para servir como lastro (Figura 5).

Segundo os autores, o ludião é um experimento rico, onde se pode focar nos princípios de Arquimedes e Pascal, na variação da pressão em um líquido com a profundidade, e na transformação isotérmica do gás confinado dento do ludião. Ademais, é enfatizado que apesar da semelhança entre o funcionamento do ludião e do submarino, já que em ambos são explicados a partir das leis da hidrostática, existem diferenças. Uma delas é que o ludião afunda pelo processo passivo causado por uma variação externa de pressão externa. Enquanto no submarino, ele afunda pelo processo passivo ativo, causado pelo bombeamento de água e pela variação da pressão interna exercida pelo ar comprimido.

Indo além de uma proposta de experimento mais sofisticado, Pimentel e Yamamura (2006) propõe uma versão do ludião bastante simples e de baixo custo. Tal proposta procurou considerar a simplicidade/facilidade na hora da montagem do experimento, que nem sempre é fácil, e o tempo de duração da aula que é destinada às aulas de Física, que nem sempre são suficientes para a realização de atividades experimentais.

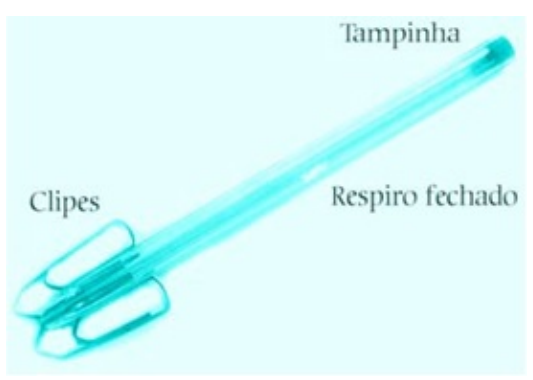

Figura 6: Versão do ludião simples proposta por Pimentel e Yamamura (2006). Fonte: Pimentel e Yamamura (2006)

Nessa versão proposta pelos autores supracitados são utilizados dois materiais de baixo custo: um corpo de caneta esferográfica BIC e dois clipes (Figura 6). Os clipes foram utilizados para servir de 
lastro, garantindo a verticalidade do ludião. Ainda segundo Pimentel e Yamamura (2006), na utilização do ludião em sala de aula, no Ensino Fundamental ou no Ensino Médio, poderão ser explorados conceitos e princípios hidrostáticos com o de Arquimedes (empuxo) e o de Pascal.

Sobre a utilização desse experimento em sala de aula, Moletta et al., (2014) destacam que a troca de experiência entre os alunos se torna mais ricas em conceitos quando fundamentada em explicações a partir dos assuntos abordados em sala de aula. Isto facilita a aprendizagem e sedimentação de conceitos científicos. Arnoni, Koike e Borges (2004), além de considerarem o ludião como uma relevante atividade experimental para o ensino, evidenciaram indícios de superação do saber inicial (conhecimento prévio) pelo saber científico (ARNONI; KOIKE; BORGES, 2004).

Atividades simples como o ludião, realizadas com material acessível podem gerar um grande interesse pela disciplina de Física, tanto nos alunos como nos próprios professores (RODRIGUES, 2014). Observase que em um experimento simples como este, envolve muitos conceitos subjacentes que devem ser explorados para que haja uma melhor compreensão pelos estudantes (ZANDOMÊNICO, 2014).

Cunha (2008) destaca que uma das vantagens desse experimento de baixo custo é possibilidade de ser desenvolvidos por alunos e por professores, utilizando ferramentas e recursos que muitas vezes as escolas já dispõem. Ademais, o baixo preço para construção, a facilidade em encontrar os materiais no dia a dia do aluno, o efeito motivacional, o desenvolvimento de competências e habilidades nos alunos da construção até o momento da interação com o objeto, e a possibilidade de observação do fenômeno são contributos que o ludião proporciona para o ensino de Física.

\section{CONSIDERAÇÕES FINAIS}

Após a análise da literatura, constatou-se que existem poucos trabalhos publicados em periódicos sobre o ludião. Através da análise das poucas pesquisas existentes, foi possível inferir que o uso de atividades experimentais de baixo custo em sala de aula, com o ludião, surgiu com o objetivo de contornar a situação da falta de laboratórios equipados nas escolas, ou pelo menos tentar amenizar esta situação. Nesse sentido, ele foi proposto e utilizado como estratégia didática para facilitar a compreensão de conceitos e fenômenos físicos.

Diante dessa estratégia, foram apontados os principais contributos do ludião para o ensino de Hidrostática: a) ser uma atividade experimental de baixo preço, caracterizada pela facilidade em encontrar os materiais no cotidiano do aluno para construção; b) potencializar o desenvolvimento de competências e habilidades nos alunos, desde a sua construção até o momento da interação com o objeto; c) ser motivacional para o aluno por ser um experimento atrativo, interativo, divertido e dinâmico.

Por fim, por permitir que o aluno possa manipular as variáveis envolvidas no fenômeno, acredita-se no potencial que o ludião possa desencadear em promover uma compreensão lúdica dos conceitos físicos subjacentes no experimento e contribuir para uma aprendizagem significativa. 


\section{Referências}

[1] ARAUJO, M. S. T.; ABIB, M. L.V.S. Atividades experimentais no ensino de física: diferentes enfoques, diferentes finalidades. Rev Bras Ens de Física, São Paulo, 25, n. 2, p. 176194, Jun. 2003. Disponível em: <http://www.scielo.br/scielo.php?script=sci_arttext\&pid=S1806$11172003000200007 \& \operatorname{lng}=e n \& n r m=i s o>$. Acesso em: 01 set., 2017.

[2] ARNONI, M. E. B.; KOIKE, L. T.; BORGES, M. A. Hora da ciência: um estudo sobre atividades experimentais no ensino do saber científico. Caderno Núcleo de Ensino. UNESP-PROGRAD, p. 282-294, 2004. Disponível em: <http://www.unesp.br/prograd/PDFNE2003/Hora\%20da\%20ciencia.pdf.>. Acesso em: 04 jul., 2017.

[3] CUNHA, C. J. G. B. L. Construção e utilização de equipamentos de baixo custo para ensino de física. Lisboa - Portugal. 100 f. [Dissertação (Programa de Pós-Graduação em Física Laboratorial, Ensino e História da Física)]. Universidade Nova de Lisboa. 2008.

[4] DUARTE, S. E. Física para o Ensino Médio usando simulações e experimentos de baixo custo: um exemplo abordando dinâmica da rotação. Cad Bras Ens Física, 29, 525 (2012).

[5] JESUS, V.L.B. de; MARLASCA, C.; TENORIO, A. Ludião versus princípio do submarino. Rev Bras Ens de Física, São Paulo, 29, n. 4, p. 599-603, 2007. Disponível em: $\quad<$ http://www.scielo.br/scielo.php?script=sci_arttext\&pid=S180611172007000400019\&lng=en\&nrm=iso $>$ Acessado em: $20 \quad$ Fev. 2018. http://dx.doi.org/10.1590/S1806-11172007000400019.

[6] MOLETTA, L.F.Y.; DRABESKI, R.G.; SANTOS, S.H.F.; BRINATTI, A.M.; SILVA, S.L.R., SILVA, J. B. Abordagem conceitual teórica e experimental sobre assuntos de hidrostática. Revista Conexão, 10, 289 (2014). Disponível em: <http://177.101.17.124/index.php/conexao/article/view/6752>. Acesso em: 01 set., 2017.

[7] MOREIRA, M. A. Grandes desafios para o ensino da Física na educação contemporânea. Rev Prof de Física, 1, 1 (2017). Disponível em: < http://periodicos.unb.br/index.php/rpf/article/view/25190>. Acesso em: 01 set., 2017.

[8] PIMENTEL, J. R.; YAMAMURA, P. Bic: Um Ludião que Funciona. A Física na escola, 7, n.1, 2006. Disponível em: < http://www1.fisica.org.br/fne/phocadownload/Vol07-Num1/v12a111.pdf >. Acesso em: 01 set., 2017.

[9] PRADO, R. T.; FERRACIOLI, L. Utilização do Diagrama $V$ em atividades experimentais de magnetismo em sala de aula de ensino médio. Rev Prof de Física, 1, n. 1, 2017. Disponível em: < http://periodicos.unb.br/index.php/rpf/article/view/26058>. Acesso em: 01 set., 2017.

[10] RODRIGUES, M. A. Atividades de extensão em locais de educação não formal para enriquecer a formação dos licenciandos em Física. Em Extensão, Uberlândia, 13, n. 1, p. 35-50, jan. / jun. 2014. 
[11] SALES, V. C. H.; VIANNA, D. M. Anais do XX Simpósio Nacional de Ensino de Física- SNEF, São Paulo, 2013, (SBF, São Paulo, 2013), p. 1-8.

[12] SILVA, J. C. X.; LEAL, C. E. S. Proposta de laboratório de física de baixo custo para escolas da rede pública de ensino médio. Rev Bras Ens de Física, São Paulo, 39, n.1, p.e1401, 2017. Disponível em: < http://www.scielo.br/scielo.php?script=sci_arttext\&pid=S1806$11172017000100501 \& \operatorname{lng}=\mathrm{en} \& n r m=\mathrm{iso} \& \operatorname{lng}=\mathrm{pt}>$. Acesso em: 01 set., 2017.

[13] SILVA, R. M; RAFAEL, R. F; NOBRE, F. A. S; ARAÚJO, K. M. G. Estudando transferência de calor utilizando folhetos de cordel científicos. Rev Prof de Física, 1, n.1, 2017. Disponível em: < http://periodicos.unb.br/index.php/rpf/article/view/25747>. Acesso em: 01 set., 2017.

[14] ZANDOMÊNICO, J. M. Uma proposta de realização de uma feira científica de física em uma escola de ensino médio. Vitória - ES. 165 f. [Dissertação (Mestrado em Ensino de Física)]. Universidade Federal do Espírito Santo. 2008. 